\title{
Tidal signatures of the thermospheric mass density and zonal wind at midlatitude: CHAMP and GRACE observations
}

\author{
C. Xiong ${ }^{1,2}$, Y.-L. Zhou ${ }^{2}$, H. Lühr ${ }^{1,2}$, and S.-Y. Ma $^{2}$ \\ ${ }^{1}$ Helmholtz Centre Potsdam, GFZ German Research Centre for Geosciences, Telegrafenberg, 14473 Potsdam, Germany \\ ${ }^{2}$ Department of Space Physics, College of Electronic Information, Wuhan University, 430079 Wuhan, China \\ Correspondence to: C. Xiong (bear@gfz-potsdam.de)
}

Received: 22 September 2014 - Revised: 7 January 2015 - Accepted: 7 January 2015 - Published: 4 February 2015

\begin{abstract}
By using the accelerometer measurements from CHAMP and GRACE satellites, the tidal signatures of the thermospheric mass density and zonal wind at midlatitudes have been analyzed in this study. The results show that the mass density and zonal wind at southern midlatitudes are dominated by a longitudinal wave- 1 pattern. The most prominent tidal components in mass density and zonal wind are the diurnal tides D0 and DW2 and the semidiurnal tides SW1 and SW3. This is consistent with the tidal signatures in the F region electron density at midlatitudes as reported by Xiong and Lühr (2014). These same tidal components are observed both in the thermospheric and ionospheric quantities, supporting a mechanism that the non-migrating tides in the upper atmosphere are excited in situ by ion-neutral interactions at midlatitudes, consistent with the modeling results of Jones Jr. et al. (2013). We regard the thermospheric dynamics as the main driver for the electron density tidal structures. An example is the in-phase variation of D0 between electron density and mass density in both hemispheres. Further research including coupled atmospheric models is probably needed for explaining the similarities and differences between thermospheric and ionospheric tidal signals at midlatitudes.
\end{abstract}

Keywords. Ionosphere (ionosphere-atmosphere interactions; mid-latitude ionosphere; wave propagation)

\section{Introduction}

The ionosphere-thermosphere (IT) system represents the transition region from Earth's atmosphere to space. Understanding ionosphere-thermosphere dynamics and electrodynamics is paramount when considering the necessity for more accurate space weather forecasts. In recent years, both observational and theoretical studies have shown that a larger part of the variability in the global IT system is associated with lower atmospheric processes, especially the influence of various waves. These waves behave as global-scale oscillations in temperature, wind, and density with periods that are harmonics of a solar day and are referred to as atmospheric "migrating" and "non-migrating" tides (e.g., Chapman and Lindzen, 1970; Forbes, 1995). Migrating tides propagate westward with the apparent motion of the sun; therefore, they are sun-synchronous and longitude independent when observed at constant local time. They are prompted primarily by the absorption of solar energy by tropospheric water and water vapor, as well as stratospheric ozone (Oberheide et al., 2002). Non-migrating tides are excited for instance by zonal asymmetries (e.g., topography, land-sea differences, longitude dependence of absorbing species) (Forbes et al., 2003) or by nonlinear interactions between the migrating diurnal tide and planetary waves (Hagan and Roble, 2001) or gravity waves (McLandress and Ward, 1994). Another important source for non-migrating tides is the latent heat release in the troposphere (Hagan and Forbes, 2002).

In general, these atmospheric tides in the universal time (UT) frame can be expressed as

$A_{n, s} \cos \left(n \Omega t+s \lambda-\phi_{n, s}\right)$,

where $A_{n, s}$ is the amplitude, $n$ denotes the harmonic of a solar day, $\Omega$ is the rotation rate of the Earth, $t$ is the universal time, $s$ is the zonal wavenumber, $\lambda$ is the longitude, and $\phi_{n, s}$ is the phase of the tides (Forbes et al., 2006). In this study, we mainly use the observations from CHAMP (CHAllenging Minisatellite Payload) and GRACE (Gravity Recovery and Climate Experiment) satellites, which are on circular, near-polar orbits. These satellites precess through $1 \mathrm{~h}$ of lo- 
cal time (LT) every 11 and 13.5 days, respectively, thus taking their daily measurements at a quasi-constant local time. When converting the tidal description from UT to LT using $t=t_{\mathrm{LT}}-\lambda / \Omega$, Eq. (1) can be expressed as

$A_{n, s} \cos \left(n \Omega t_{\mathrm{LT}}+(s-n) \lambda-\phi_{n, s}\right)$.

For migrating tides $(s=n)$, the amplitude are longitude independent $(s-n=0)$ in the local time frame. While nonmigrating tides $(s \neq n)$ will present longitudinal patterns at wavenumbers $|s-n|$. In accordance with previous definitions, throughout this study we will use the notation DWs and DEs for labeling the tidal components. The first letters $\mathrm{D}, \mathrm{S}$, and $\mathrm{T}$ stand for diurnal, semidiurnal, and terdiurnal; the second letters $\mathrm{E}$ and $\mathrm{W}$, for eastward or westward propagating; and the final number quantifies the azimuthal wavenumber. D0 represents a wave that is increasing and decreasing simultaneously at all longitudes with a diurnal period. Stationary planetary waves are labeled as SPWs and the number at the end quantifies the number of maxima around the globe. The phase of the tides defines the time when the wave crest passes the $0^{\circ}$ longitude meridian, while in the case of SPWs, the longitude of the wave maximum is given.

Due to the rapid development of the upper atmospheric observations in the past decade, significant progress has been made in the investigation of the coupling of the upper atmosphere and ionosphere. At equatorial and low latitude regions, the longitudinal wavenumber-4 (WN4) and wavenumber-3 (WN3) patterns have been widely studied, based on model simulations and observations from sunsynchronous and slowly precessing platforms in space (e.g., Sagawa et al., 2005; Immel et al., 2006; England et al., 2006, 2010; Forbes et al., 2006; Lühr et al., 2008, 2012; Oberheide et al., 2009, 2011b; Liu et al., 2009; Häusler and Lühr, 2009). These WN4/WN3 patterns are considered to be associated with the eastward-propagating non-migrating tides DE3/DE2, that are primary excited by latent heat release in the tropical troposphere (Hagan and Forbes, 2003; Immel et al., 2006; Wan et al., 2010). Hagan et al. (2009) reported the existence of stationary planetary wave-4 (SPW4) oscillation in the upper mesosphere and lower thermosphere (MLT) region, caused by the nonlinear interaction between DE3 and the migrating tide DW1. Since then, the importance of stationary planetary waves, SPW4/SPW3, contributing to the longitudinal WN4/WN3 patterns in the upper atmosphere, has also been supported by both model simulations (e.g., Oberheide et al., 2011a; Pancheva et al., 2012) and in situ observations (e.g., Kil et al., 2010; Lühr and Manoj, 2013; Xiong and Lühr, 2013; Chang et al., 2013).

At midlatitudes, in our recent work Xiong and Lühr (2014), we have reported prominent longitudinal wave-1 and wave-2 patterns in electron density of the southern and northern midlatitude summer nighttime anomaly (MSNA) features, respectively. The MSNA refers to the phenomena of nighttime electron density anomalous enhancements at midlatitudes during local summer seasons. In the Southern
Hemisphere, the MSNA (also named Weddell Sea anomaly - WSA) was first observed by ground-based ionosondes in the 1950s (e.g., Bellchambers and Piggott, 1958; Penndorf, 1965) and further detailed by using satellite observations in recent years (Burns et al., 2008; Lin et al., 2009; He et al., 2009). The northern WSA-like features (with two electron density anomalous regions) have later been widely investigated by various observations (Lin et al., 2009, 2010; Thampi et al., 2009; Liu et al., 2010). The generation of the MSNA is still an open issue, and several potential mechanisms have been proposed that try to explain the phenomenon. The wind mechanism is consistent with most of the observations, which can be interpreted as a combined result of thermospheric wind, solar photo-ionization, and the local magnetic field configuration (Rishbeth, 1967, 1968; Dudeney and Piggott, 1978; He et al., 2009). Other mechanisms such as the transportation of plasma from the dayside ionosphere and the downward flux from the plasmasphere have also been proposed (Burns et al., 2008). By employing a three-dimensional physics-based ionosphere model, SAMI3 (Sami3 is Also a Model of the Ionosphere), coupled with the Thermosphere-Ionosphere Electrodynamics General Circulation Model (TIE-GCM) and the Global Scale Wave Model, Chen et al. (2013) reported a clear eastward movement of the southern MSNA (see their Fig. 2b). They further explained that the standing diurnal tide (D0) dominates the vertical neutral wind causing the southern MSNA feature, and the tide manifests itself as a diurnal eastward-propagating wave-1 pattern. Our recent study confirmed the eastward movement of the MSNA in both hemispheres from in situ measurements of the CHAMP and GRACE missions (Xiong and Lühr, 2014). From the tidal perspective, the prominent MSNA features have further been interpreted as the simultaneous constructive interferences of the tidal components D0, DW2, and stationary planetary wave SPW1 in the Southern Hemisphere, and DE1, D0, and DW2 in the Northern Hemisphere. The non-migrating tidal spectrum for the electron density in the topside ionosphere on global scale for different seasons at both solar maximum and minimum conditions have been further reported by Xiong et al. (2014a).

Until now, the physical mechanisms of the tides that modulate the topside ionosphere at middle and high latitudes have not been well understood. As the zonal wind is an important driver of electrodynamics in the upper atmosphere, knowing the tidal effects on the zonal wind and thermospheric mass density might help us to better understand the coupling mechanism of the IT system.

In this study, we will focus on the tidal effects of the thermospheric mass density and zonal wind that are associated with the MSNA features. The high resolution and continuous mass density and zonal wind measurements from the CHAMP and GRACE missions provide us the opportunity for such a study. In Sect. 2, we first introduce the data and processing approach. Then, we present the tidal spectra of the thermospheric mass density and zonal wind in Sect. 3. 
The interpretation of the tidal features in the thermosphere and ionosphere and a comparison with earlier studies will be given in Sect. 4.

\section{Data and processing approach}

\subsection{Data sets}

The thermospheric mass density and zonal wind data used in this study are deduced from the observations of accelerometers on board the CHAMP and GRACE satellites. The CHAMP spacecraft was launched on 15 July 2000 into a near-circular polar orbit (inclination: $87.3^{\circ}$ ) with an initial altitude of $456 \mathrm{~km}$. By the end of the mission, 19 September 2010 , the orbit had decayed to $250 \mathrm{~km}$. The orbital period is about $93 \mathrm{~min}$, thus circling the Earth about 15 times per day. The orbital plane covers all local times within 131 days, at a rate of $1 \mathrm{~h}$ in local time per 11 days. The Spatial Triaxial Accelerometer for Research (STAR) accelerometer developed by the Centre National d'Etudes Spatiales (CNES) on board CHAMP measures non-conservative forces exerted on the satellite with a resolution of $<10^{-9} \mathrm{~m} \mathrm{~s}^{-2}$ in the along-track and cross-track directions (Reigber et al., 2002). This corresponds to a resolution of $<10^{-14} \mathrm{~kg} \mathrm{~m}^{-3}$ for mass density and $<10 \mathrm{~m} \mathrm{~s}^{-1}$ for the zonal wind measurements (Doornbos et al., 2010).

The GRACE mission consists of two identical spacecraft separated along-track by approximately $170-220 \mathrm{~km}$. The twin GRACE spacecraft were launched on 17 March 2002 into a near-circular polar orbit (inclination: $89^{\circ}$ ) with an initial altitude of about $490 \mathrm{~km}$. By the end of 2012, the altitudes of the two spacecraft have gone down to about $460 \mathrm{~km}$ (Xiong et al., 2014b). The local time of the orbital plane precesses by $4.5 \mathrm{~min}$ every day, taking about 161 days to cover all local times. Both spacecraft are equipped with a three-axis SuperSTAR accelerometer with a resolution of $<10^{-10} \mathrm{~m} \mathrm{~s}^{-2}$ to observe the non-gravitational forces (Tapley et al., 2004; Doornbos et al., 2010), which is about an order of magnitude better than the CHAMP mission.

\subsection{Processing approach}

The mass density data used in this study are derived from the calibrated accelerometer measurements in spacecraft $x$ direction (along-track), together with the satellite attitude data, a structure model etc. Details about the processing of accelerometer measurements to obtain air mass density and cross-track wind data have been given by Doornbos et al. (2010) and references therein. In order to exclude variations caused by orbital height changes, the mass densities are normalized to common altitude. The method to obtain normalized densities at a fixed height is given as

$\rho_{\text {Mea }}\left(h_{0}\right)=\rho_{\text {Mea }}(h) \cdot \frac{\rho_{\text {Mod }}\left(h_{0}\right)}{\rho_{\text {Mod }}(h)}$, where $h_{0}$ is the reference altitude, with values of 400 and $500 \mathrm{~km}$ for CHAMP and GRACE, respectively; $h$ is the actual altitude of the satellites; $\rho_{\text {Mod }}(h)$ and $\rho_{\text {Mod }}\left(h_{0}\right)$ are the densities calculated from NRLMSISE-00 at the satellite positions and at the reference altitude; $\rho_{\mathrm{Mea}}(h)$ and $\rho_{\mathrm{Mea}}\left(h_{0}\right)$ are the observed density and normalized density, respectively. The wind data do not require altitude normalization since the thermospheric wind velocity depends only weakly on altitude.

The purpose of the study is to compare the tidal effects on the thermospheric mass density and zonal wind with that of the electron density; therefore, the same method for deriving the tidal components has been used as described in Xiong and Lühr (2014). The general mathematical formulation of the relationship between longitudinal patterns in satellite observations and the non-migrating tidal description in the Earth-fixed frame is given by Forbes et al. (2006) and Häusler and Lühr (2009). In this study, the thermospheric mass density and zonal wind data has been first sorted into longitude $\left(15^{\circ}\right) \times$ local time $(1 \mathrm{~h})$ bins. Then, to suppress the prominent migrating tides, the longitudinal mean value has been subtracted hour by hour. After that, these mean-free data are processed by a Fourier transform in order to obtain the longitudinal patterns for each wavenumber up to 4 from which we identify visually the prominent tides. In the next step, a tidal model, containing all tidal and stationary components within the bandwidth of interest, is fitted to the longitudinal patterns. From the fitting we derive the amplitudes and phases of all tidal components. For validating our decomposition, we check the residuals, which are defined as observations minus synthetic signals, for systematic patterns. If no or small systematic patterns appear, the synthetic signal is considered reliable. The same approach has been used by Xiong and Lühr $(2013,2014)$ for investigating the tidal signatures of the ionosphere at low and middle latitudes.

\section{Results}

In order to compare the tidal features of the topside ionosphere that are related to MSNA, as reported by Xiong and Lühr (2014), the same magnetic latitude (MLAT) range $( \pm 40$ to $\pm 60^{\circ}$ ) has been selected for the thermospheric mass density and zonal wind measurements. As the background thermospheric mass density is largely controlled by solar activity and magnetic storms, data from solar minimum years (from 2007 to 2009 , mean P10.7 = 71 sfu) have been selected for the mass density to avoid their influence on our tidal signatures analysis. In contrast, the wind shows much less dependence on solar activity, as shown by Liu et al. (2006). Unfortunately, the wind signals at CHAMP altitude are too weak and unreliable during solar minimum conditions. For that reason we have derived the tidal signatures of the zonal wind from the more active years between 2001 and 2003 (mean $\mathrm{P} 10.7=163 \mathrm{sfu}$ ). The measurements have been further di- 

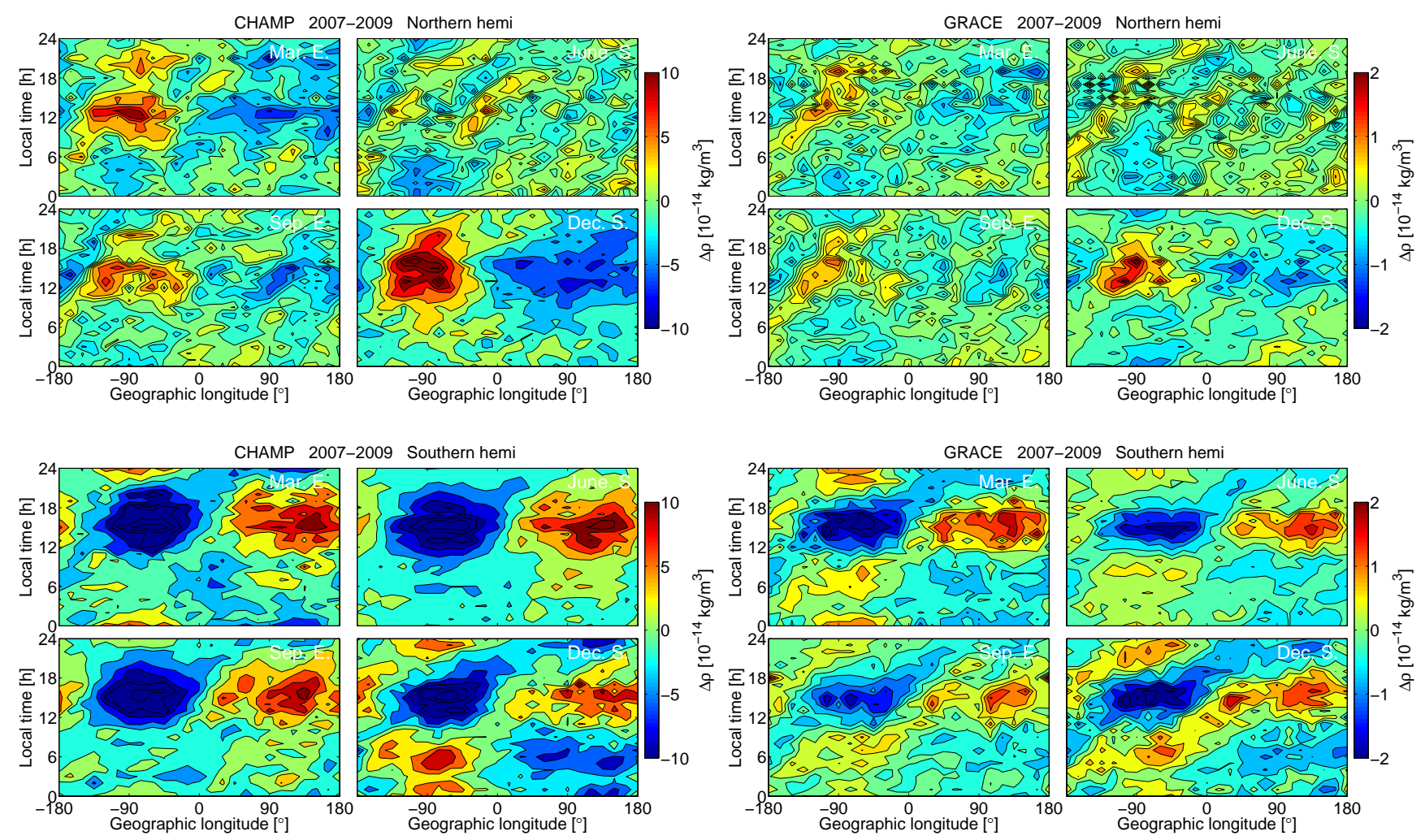

Figure 1. Local time versus longitudinal distribution of thermospheric mass density for four seasons in the Northern (top) and Southern (bottom) hemispheres both from CHAMP (left) and GRACE (right) observations.

vided into four seasons, centered around the March equinox, June solstice, September equinox, and December solstice. For each season overlapping periods of 131 and 161 days are needed to cover all 24 local time hours for CHAMP and GRACE, respectively. Days with planetary geomagnetic activity index (Ap) of $>30$ are excluded to reduce the influence of sever magnetic disturbances. The observations presented here are averages of the seasons over 3 years. Therefore, the results favor those tides which remain steady over long time. Tides occurring occasionally will not contribute much to the signals presented here.

\subsection{Tidal features of the mass density at midlatitudes}

As we discussed above, the longitudinal wave structures observed by near-polar orbiting satellites can be caused by many different tidal components. By analyzing the propagating phase of the wave in local time, different tidal components can be separated. For each season, the mass density observations $(\rho)$ is first sorted into MLAT $\left(1^{\circ}\right)$ and geographic longitude $\left(15^{\circ}\right)$ bins. Then, the mass density between \pm 40 to $\pm 60^{\circ}$ MLAT is averaged for each local time hour. To suppress the migrating tides the longitudinal mean value is subtracted hour by hour.

Figure 1 presents the local time versus longitudinal distribution of $\Delta \rho$ for four seasons in the Northern (top) and
Southern (bottom) hemispheres both from CHAMP (left) and GRACE (right) mass density observations. Here $\Delta \rho$ means that the longitudinal mean value of $\rho$ has been subtracted. At CHAMP altitude $\Delta \rho$ is found to be largest throughout the year around $150-30^{\circ} \mathrm{W}$ during 12:00-21:00 LT (except for the June solstice) in the Northern Hemisphere, while in the Southern Hemisphere a minimum value of $\Delta \rho$ appears in the same longitude region during the same local time. The peak value of $\Delta \rho$ in the Southern Hemisphere appears around 30$150^{\circ} \mathrm{E}$ during 12:00-21:00 LT, which is about $180^{\circ}$ apart in longitude from the $\Delta \rho$ peak in the Northern Hemisphere. Interestingly, a mixture of longitudinal wave structures can be seen in the Northern Hemisphere during the June solstice. In the Southern Hemisphere during the December solstice, a second peak appears around $150-30^{\circ} \mathrm{W}$ during 21:0009:00 LT. The two peaks can be considered as part of a wave1 pattern, which is consistent with our earlier report about the wave-1 pattern of the southern MSNA feature (Xiong and Lühr, 2014).

The mass density at GRACE altitude exhibits mixtures of longitudinal wave structures in the Northern Hemisphere during the four seasons, the peak value of $\Delta \rho$ around 150 $30^{\circ} \mathrm{W}$ during 12:00-21:00 LT is only prominent during the December solstice. In the Southern Hemisphere, the peak value of $\Delta \rho$ can also be found around $30-150^{\circ} \mathrm{E}$ during 

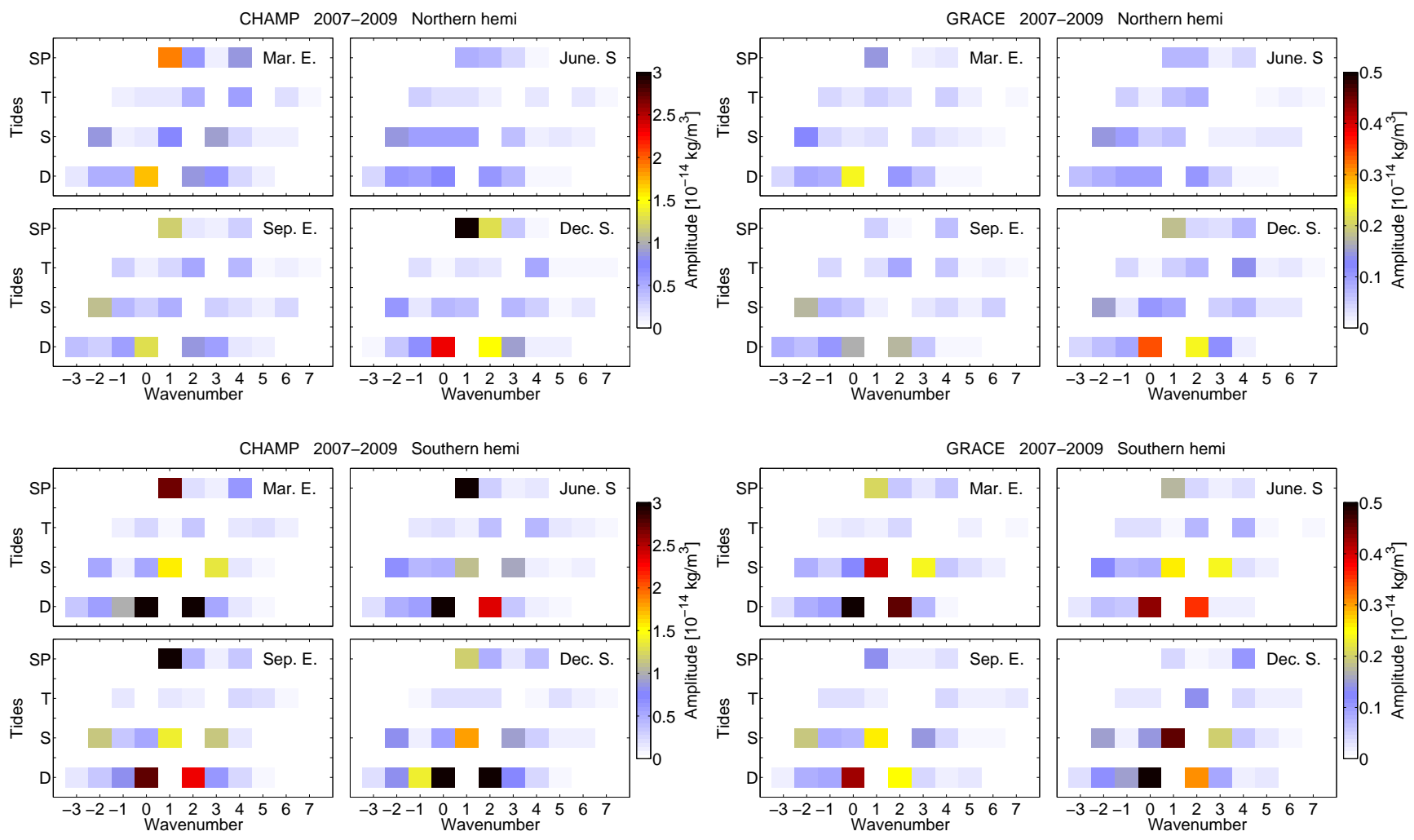

Figure 2. Spectra of the tidal and stationary components in mass density for four seasons in the Northern (top) and Southern (bottom) hemispheres both from CHAMP (left) and GRACE (right) observations.

12:00-21:00 LT. The larger value of $\Delta \rho$ around $150-30^{\circ} \mathrm{W}$ during 21:00-09:00 LT throughout the whole year makes the wave-1 pattern much more prominent in the Southern Hemisphere at GRACE altitude, compared to that at CHAMP altitude.

Figure 2 presents the amplitudes of the full non-migrating tidal and stationary spectrum for four seasons separately in the Northern (top) and Southern (bottom) hemispheres both from CHAMP (left) and GRACE (right) mass density observations. As can be seen, in the Northern Hemisphere SPW1 and D0 are found to be the most prominent stationary and tidal components throughout the year both at CHAMP and GRACE altitudes, but this is not so obvious around the June solstice. During the December solstice DW2 also shows comparable amplitudes. The semidiurnal tidal component SE2 is relatively large during the September equinox. In the Southern Hemisphere, spectral amplitudes are larger. SPW1, D0, and DW2 are found to be prominent throughout the whole year. The semidiurnal components SW1 and SW3 are also presented at all seasons with somewhat smaller amplitudes. Similar to the Northern Hemisphere, the tidal component SE2 shows comparable amplitudes during the September equinox in the Southern Hemisphere. To make it easier for the reader, the numerical values of amplitudes and phases for the two most important diurnal and semidiurnal tidal components are listed in Table 1.

\subsection{Tidal features of the zonal wind at midlatitudes}

As there are no zonal wind data from GRACE, Fig. 3 only presents the local time versus longitudinal distribution of zonal wind for four seasons in the Northern (left) and Southern (right) hemispheres from CHAMP measurements. As already mentioned above, the longitudinal mean value has been subtracted hour by hour to suppress the migrating tides. A mixture of longitudinal wave patterns are shown in the Northern Hemisphere, while a prominent wave-1 structure can be found in the Southern Hemisphere throughout the year. When compared to the longitudinal wave structures of the mass density in the Southern Hemisphere, the crest of wave- 1 is found to be out of phase by about $12 \mathrm{~h}$ between these two neutral quantities. The amplitudes of the non-migrating tidal and stationary spectrum in the Northern (left) and Southern (right) hemispheres from CHAMP zonal wind measurements are presented in Fig. 4. Similar to Table 1, the amplitudes and phases of the two most important diurnal and semidiurnal tidal components from the zonal wind data are listed in Table 2. Prominent tidal components, D0, DW2, and SW1, can be found in both hemispheres throughout the whole year. Different from the tidal 
Table 1. Amplitudes and phases of diurnal tides D0 and DW2 as well as semidiurnal tides SW1 and SW3 from the thermospheric mass density measurements during the years 2007-2009.

\begin{tabular}{|c|c|c|c|c|c|c|c|c|c|}
\hline \multicolumn{10}{|c|}{ Thermospheric mass density } \\
\hline & & \multicolumn{4}{|c|}{ CHAMP } & \multicolumn{4}{|c|}{ GRACE } \\
\hline & & \multicolumn{2}{|c|}{ Northern Hemisphere } & \multicolumn{2}{|c|}{ Southern Hemisphere } & \multicolumn{2}{|c|}{ Northern Hemisphere } & \multicolumn{2}{|c|}{ Southern Hemisphere } \\
\hline & & $\begin{array}{c}\text { Amplitude } \\
{\left[10^{-14} \mathrm{~kg} \mathrm{~m}^{-3}\right]}\end{array}$ & $\begin{array}{c}\text { Phase } \\
{[\mathrm{h}]}\end{array}$ & $\begin{array}{c}\text { Amplitude } \\
{\left[10^{-14} \mathrm{~kg} \mathrm{~m}^{-3}\right]}\end{array}$ & $\begin{array}{c}\text { Phase } \\
{[\mathrm{h}]}\end{array}$ & $\begin{array}{c}\text { Amplitude } \\
{\left[10^{-14} \mathrm{~kg} \mathrm{~m}^{-3}\right]}\end{array}$ & $\begin{array}{c}\text { Phase } \\
{[\mathrm{h}]}\end{array}$ & $\begin{array}{c}\text { Amplitude } \\
{\left[10^{-14} \mathrm{~kg} \mathrm{~m}^{-3}\right]}\end{array}$ & $\begin{array}{c}\text { Phase } \\
{[\mathrm{h}]}\end{array}$ \\
\hline \multirow[t]{4}{*}{ Mar } & D0 & 1.69 & 20.03 & 3.47 & 7.80 & 0.23 & 20.36 & 0.61 & 7.97 \\
\hline & DW2 & 0.85 & 8.66 & 3.15 & 22.64 & 0.10 & 10.98 & 0.45 & 22.10 \\
\hline & SW1 & 0.78 & 1.63 & 1.55 & 0.92 & 0.03 & 0.41 & 0.40 & 11.80 \\
\hline & SW3 & 0.93 & 8.13 & 1.33 & 8.53 & 0.04 & 6.08 & 0.24 & 7.04 \\
\hline \multirow[t]{4}{*}{ Jun } & D0 & 0.79 & 18.92 & 3.02 & 7.43 & 0.09 & 20.43 & 0.43 & 8.70 \\
\hline & DW2 & 0.61 & 10.37 & 2.34 & 22.31 & 0.10 & 11.20 & 0.35 & 23.07 \\
\hline & SW1 & 0.56 & 0.39 & 1.09 & 11.91 & 0.06 & 0.85 & 0.26 & 11.66 \\
\hline & SW3 & 0.40 & 6.43 & 0.96 & 7.19 & 0.01 & 5.26 & 0.24 & 6.76 \\
\hline \multirow[t]{4}{*}{ Sep } & D0 & 1.31 & 19.04 & 2.73 & 8.00 & 0.16 & 20.25 & 0.42 & 7.87 \\
\hline & DW2 & 0.84 & 7.98 & 2.31 & 22.72 & 0.17 & 9.85 & 0.25 & 23.11 \\
\hline & SW1 & 0.47 & 14.99 & 1.37 & 0.30 & 0.01 & 1.52 & 0.25 & 11.18 \\
\hline & SW3 & 0.30 & 11.06 & 1.15 & 7.43 & 0.02 & 10.69 & 0.14 & 6.50 \\
\hline \multirow[t]{4}{*}{ Dec } & D0 & 2.30 & 20.71 & 3.89 & 7.81 & 0.34 & 20.11 & 0.60 & 8.19 \\
\hline & DW2 & 1.54 & 7.76 & 3.42 & 22.83 & 0.23 & 9.45 & 0.30 & 22.15 \\
\hline & SW1 & 0.37 & 6.32 & 1.79 & 11.32 & 0.08 & 6.50 & 0.45 & 11.37 \\
\hline & SW3 & 0.44 & 10.34 & 0.89 & 5.42 & 0.5 & 11.97 & 0.20 & 6.70 \\
\hline
\end{tabular}

signatures in the electron and mass density, the amplitude of DW2 in zonal wind exceeds D0 during most of the seasons in both hemispheres (except the solstice seasons in the Southern Hemisphere). We will give a more detailed discussion about the tidal amplitudes and phases between the three quantities in the next section.

\section{Discussion}

The study presented here has provided the tidal signatures of the upper atmospheric mass density and zonal wind at midlatitudes for different seasons. Similar to the MSNA, as reported by Xiong and Lühr (2014), the in situ mass density and zonal wind observations from CHAMP and GRACE at midlatitudes also exhibit prominent longitudinal wave-1 patterns in the Southern Hemisphere, especially during local summer. Since we consider the wind to be closely related to the driving mechanism, we will first discuss the features of the zonal wind.

\subsection{Zonal wind observations and model predictions}

As already revealed by previous studies there are generally two major potential coupling mechanisms between the neutral atmosphere and the ionosphere. The first is upward propagation of non-migrating tides, since many of them are generated in the troposphere and stratosphere due to latent heat release and planetary wave/migrating tide interactions (Eng- land et al., 2010; Wu et al., 2012). Some of these tides can propagate directly to the upper thermosphere and generate the equally spaced patterns in longitude. The second is the E region wind dynamo. In this case, the non-migrating tides are not required to propagate all the way to the upper thermosphere, but electrodynamic coupling takes place between $\mathrm{E}$ and $\mathrm{F}$ regions, causing ion drifts at $\mathrm{F}$ region. As the $E \times B$ drift mainly affects the $\mathrm{F}$ region at equatorial latitudes, it will not be important for the longitudinal wave patterns of the plasma at midlatitudes. However, the wave patterns of the MSNA as reported by Chen et al. (2013) and Xiong and Lühr (2014) imply that there should be some other coupling mechanism at midlatitudes. By model simulations, Jones Jr. et al. (2013) revealed that at low and middle latitudes the nonmigrating tides of the zonal wind could be generated in situ through ion-neutral interactions due to the longitudinal ionospheric density variations imposed by the actual geomagnetic field configuration. Their results also show that the primary non-migrating diurnal tides excited in situ by ion-neutral interaction at middle latitudes are D0 and DW2; the secondary semidiurnal tides are SW1 and SW3 (see their Fig. 5).

Our observations confirm that the tidal components D0 and DW2 are clearly dominating the spectrum of thermospheric zonal wind at midlatitudes during all seasons (see Fig. 4). As opposed to the simulation, DW2 is on average slightly larger than D0. The phase of DW2 in the Northern and Southern hemispheres differs by about $12 \mathrm{~h}$ (see Table 2). The same is in principle true for D0. Unfortunately, 

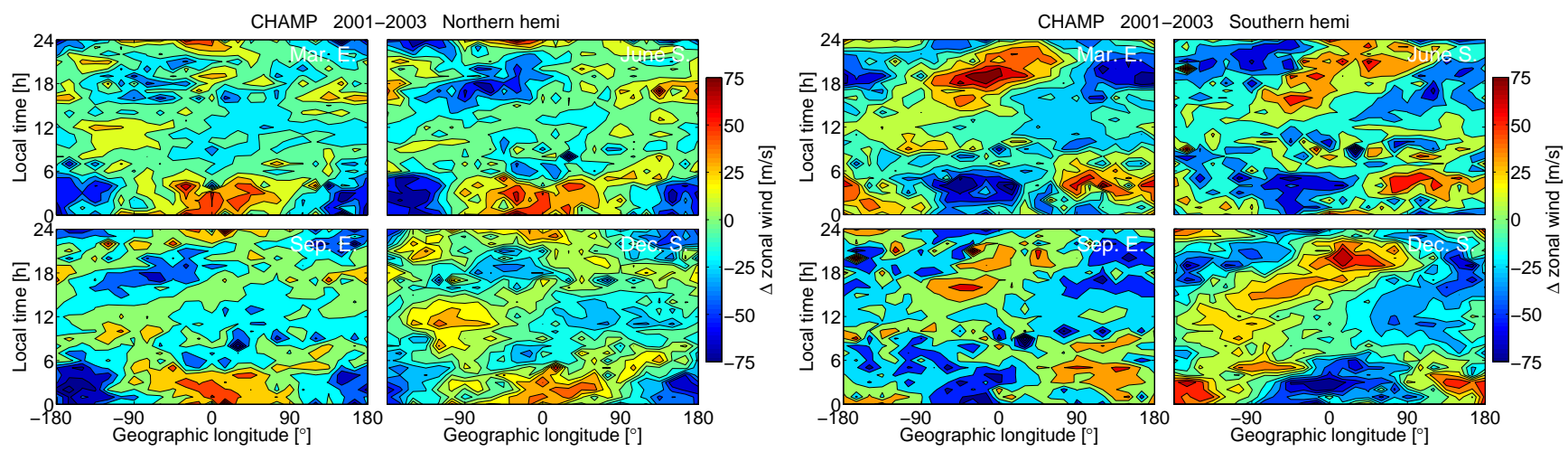

Figure 3. Local time versus longitudinal distribution of zonal wind for four seasons in the Northern (left) and Southern (right) hemispheres from CHAMP measurements.
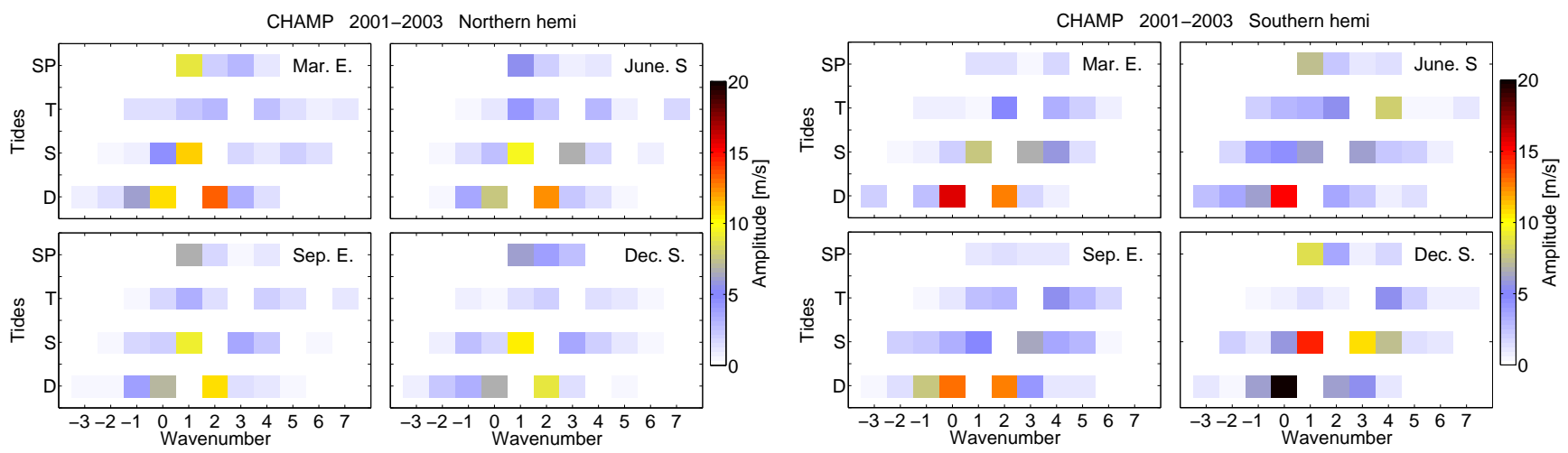

Figure 4. Spectra of the tidal and stationary components in zonal wind from the Northern (left) and Southern (right) hemispheres from CHAMP measurements.

Jones Jr. et al. (2013) reported no phase values for comparison. They suggested a possible generation mechanism for the patterns in the wind that is based on an in situ interaction between the diurnal migrating tide DW1 and the stationary planetary wave SPW1. Our result showed that the phase of the wind tidal components D0 and DW2 are rather similar during all the seasons (see Table 2). This means that the sum of tidal signatures has extrema near 0 and $180^{\circ}$ longitude (cf. Fig. 3). Conversely, zero-crossing appears around $\pm 90^{\circ}$. These are the longitudes towards which the magnetic dipole axis is tilted. Jones Jr. et al. (2013) clearly showed that the prominence of the wave-1 tides appear when the actual geomagnetic field configuration is considered.

We use the same line of arguments to explain the prominent semidiurnal components SW1 and somewhat smaller SW3. In this case, it is the interaction of the migrating tide SW2 with SPW1. Jones Jr. et al. (2013) also predicted a prominent SW1 at middle latitudes and a smaller SW3. Also SW1 and SW3 vary practically in-phase and the two hemispheres vary again in anti-phase $(6 / 12 \mathrm{~h}$ difference, see Table 2). Overall, our wind observations provide a good validation of the presented simulation results.

\subsection{Comparison of mass density variations with ionospheric MSNA}

The ionospheric phenomena of MSNA have intensively been studied (e.g., Bellchambers and Piggott, 1958; Penndorf, 1965; Burns et al., 2008; He et al., 2009; Thampi et al., 2009; Lin et al., 2009, 2010; Liu et al., 2010). All these authors revealed that during local summer, the electron density in these regions is much larger at nighttime than at daytime. By using a similar approach as shown in Fig. 1 of Liu et al. (2010), we subtracted the thermospheric mass density at daytime from the density at nighttime. But no prominent mass density enhancements can be found either in the Weddell Sea region or in the northern Atlantic (East Asian) regions during local summer. An explanation can be inferred from the large diurnal variations of the mass density that is masking the relatively small tidal effects. However, when the longitudinal mean value has been subtract to suppress the migrating tides, prominent wave- 1 patterns of the mass density can be found in the Southern Hemisphere, which are similar to the wave-1 patterns of the southern ionospheric MSNA. For a quantitative assessment of relative tidal amplitude, we normalized D0 to the migrating tide DW1. During local summer we ob- 
Table 2. Same as Table 1, but for the CHAMP zonal wind measurements during the years 2001-2003.

\begin{tabular}{|c|c|c|c|c|c|}
\hline \multicolumn{6}{|c|}{ Thermospheric zonal wind } \\
\hline & & \multicolumn{4}{|c|}{ CHAMP } \\
\hline & & \multicolumn{2}{|c|}{ Northern Hemisphere } & \multicolumn{2}{|c|}{ Southern Hemisphere } \\
\hline & & $\begin{array}{c}\text { Amplitude } \\
{\left[\mathrm{m} \mathrm{s}^{-1}\right]}\end{array}$ & $\begin{array}{c}\text { Phase } \\
{[\mathrm{h}]}\end{array}$ & $\begin{array}{c}\text { Amplitude } \\
{\left[\mathrm{m} \mathrm{s}^{-1}\right]}\end{array}$ & $\begin{array}{c}\text { Phase } \\
{[\mathrm{h}]}\end{array}$ \\
\hline \multirow[t]{4}{*}{ Mar } & D0 & 10.67 & 1.68 & 15.77 & 19.68 \\
\hline & DW2 & 13.38 & 2.13 & 12.69 & 15.66 \\
\hline & SW1 & 11.05 & 1.83 & 7.53 & 14.02 \\
\hline & SW3 & 1.82 & 0.45 & 6.56 & 14.26 \\
\hline \multirow[t]{4}{*}{ Jun } & D0 & 7.64 & 3.24 & 15.28 & 19.26 \\
\hline & DW2 & 12.27 & 1.87 & 3.63 & 13.24 \\
\hline & SW1 & 9.68 & 1.07 & 6.21 & 6.91 \\
\hline & SW3 & 6.65 & 1.08 & 6.12 & 9.55 \\
\hline \multirow[t]{4}{*}{ Sep } & D0 & 7.13 & 1.06 & 12.97 & 19.32 \\
\hline & DW2 & 10.63 & 2.36 & 12.51 & 13.23 \\
\hline & SW1 & 9.35 & 2.08 & 5.22 & 5.41 \\
\hline & SW3 & 3.44 & 1.72 & 6.53 & 7.38 \\
\hline \multirow[t]{4}{*}{ Dec } & D0 & 6.81 & 0.67 & 23.50 & 16.41 \\
\hline & DW2 & 8.90 & 2.63 & 6.05 & 15.42 \\
\hline & SW1 & 10.58 & 2.38 & 14.46 & 6.83 \\
\hline & SW3 & 3.69 & 10.57 & 10.81 & 8.20 \\
\hline
\end{tabular}

tain at CHAMP altitude for the Northern (Southern) Hemisphere a ratio of mass density of $0.06(0.12)$. The related ratio for electron density at the Northern (Southern) Hemisphere is 0.34 (1.0) (see Table 1 of Xiong and Lühr, 2014). This result shows that compared to the electron density, the effects of tide D0 in the thermospheric mass density is less by a factor of 6 to 8 at midlatitudes. As D0 is found to be the most prominent tidal component in both thermospheric mass density and electron density at midlatitudes; it may partly explain why the MSNA features can be seen directly in the F region electron density distribution, but not in the thermospheric mass density. Additionally, the interaction between the neutral wind and geomagnetic main field also contributes partly to the development of the ionospheric MSNA features. After subtracting the longitudinal mean, a coincidence of wave-1 structure in electron density, mass density as well as the zonal wind appears, implying that these non-migrating tides in the upper atmosphere are a result of a common driving mechanism. We think that the ion-neutral interaction in the upper ionosphere, as described by Jones Jr. et al. (2013), is the primary cause.

As reported by Xiong and Lühr (2014), the northern MSNA shows a prominent eastward-propagating wave-2 pattern in electron density, and the dominating tidal and stationary components are found to be DE1, SPW1, D0, and DW2 (ordered by magnitude). However, this wave- 2 pattern can neither be found in the zonal wind nor in thermospheric mass density observations in the Northern Hemisphere. Therefore, we believe that additional interactions might exist, for exam- ple, between the zonal wind and the geomagnetic field, additionally controlling the distribution of electron density in the $F$ region. Further studies are needed for clarifying the issue.

The amplitudes and phases of diurnal tidal components DE1, D0, and DW2, as well as semidiurnal components SW1 and SW2 from electron density observations are listed in Table 3 . A closer phase comparison of the most prominent tidal components in the ionospheric and thermospheric annually averaged quantities is shown in Table 4. The most interesting is tide D0. It appears at very similar phases in both electron and mass density, around 20:00 UT and 08:00 UT in the Northern and Southern hemispheres, respectively. This phase relationship for D0 in both neutral and ionization quantities suggests that an upward and downward motion of the thermospheric background controls at least partly the variation of electron density in the F region (see Xiong and Lühr, 2014). According to the Chapman layer formula, a larger atmospheric scale height enhances the ionization rate. For the other tidal components we cannot find such a phase relationship between neutral and ionized constituents.

Another mechanism exciting the tidal components in mass density is the converging and diverging zonal wind. As explained in the previous section, we find maxima of eastward wind shortly after midnight in the Northern Hemisphere (Fig. 3). This implies a convergence and air upwelling around $90^{\circ} \mathrm{E}$ in longitude as well as a divergence and downwelling around $90^{\circ} \mathrm{W}$. The opposite wind direction are inferred from the tidal components D0 and DW2 shortly after noon. Consistent with this notion, we found at CHAMP altitude in the Northern Hemisphere mass density enhancements around $90^{\circ} \mathrm{W}$ and depletions around $90^{\circ} \mathrm{E}$ shortly after noon (Fig. 1). The opposite conditions prevail for density and wind in the Southern Hemisphere with mass density depletions around $90^{\circ} \mathrm{W}$ and enhancement around $90^{\circ} \mathrm{E}$ in longitude. This causal relationship suggest that the zonal wind is the main driver for the primary tides in mass density.

For completeness we want to comment on the appearance of the tide SE2 during the September equinox. This tidal component has earlier been observed (e.g., in thermospheric temperature at low-middle latitudes) and is related to wave-4 pattern caused by deep tropical convection in the troposphere (e.g., Oberheide et al., 2011a).

\section{Summary}

Based on accelerometer observations from CHAMP and GRACE satellites, tidal signatures of thermospheric mass density and zonal wind at midlatitudes have been analyzed in this study. The main results are summarized as follows:

1. The zonal wind at midlatitudes is dominated by longitudinal wave-1 signatures; primary tidal components are D0, DW2, SW1, and SW3 in both hemispheres. The amplitude and phase relationships are consistent with the generation of non-migrating tides from an interaction 
Table 3. Same as Table 1, but for the electron density measurements during the years 2007-2009. The prominent diurnal tide DE1 has also been listed here.

\begin{tabular}{|c|c|c|c|c|c|c|c|c|c|}
\hline \multicolumn{10}{|c|}{ Electron density } \\
\hline & & \multicolumn{4}{|c|}{ CHAMP } & \multicolumn{4}{|c|}{ GRACE } \\
\hline & & \multicolumn{2}{|c|}{ Northern Hemisphere } & \multicolumn{2}{|c|}{ Southern Hemisphere } & \multicolumn{2}{|c|}{ Northern Hemisphere } & \multicolumn{2}{|c|}{ Southern Hemisphere } \\
\hline & & $\begin{array}{l}\text { Amplitude } \\
{\left[10^{10} \mathrm{~m}^{-3}\right]}\end{array}$ & $\begin{array}{l}\text { Phase } \\
{[\mathrm{h}]}\end{array}$ & $\begin{array}{l}\text { Amplitude } \\
{\left[10^{10} \mathrm{~m}^{-3}\right]}\end{array}$ & $\begin{array}{l}\text { Phase } \\
{[\mathrm{h}]}\end{array}$ & $\begin{array}{l}\text { Amplitude } \\
{\left[10^{10} \mathrm{~m}^{-3}\right]}\end{array}$ & $\begin{array}{l}\text { Phase } \\
{[\mathrm{h}]}\end{array}$ & $\begin{array}{l}\text { Amplitude } \\
{\left[10^{10} \mathrm{~m}^{-3}\right]}\end{array}$ & $\begin{array}{c}\text { Phase } \\
{[\mathrm{h}]}\end{array}$ \\
\hline \multirow[t]{5}{*}{ Mar } & DE1 & 1.44 & 2.15 & 0.86 & 10.02 & 0.47 & 2.18 & 0.32 & 8.34 \\
\hline & D0 & 1.14 & 20.37 & 4.30 & 6.70 & 0.33 & 19.36 & 1.65 & 6.45 \\
\hline & DW2 & 0.47 & 13.51 & 2.42 & 15.61 & 0.15 & 11.42 & 0.77 & 15.58 \\
\hline & SW1 & 0.48 & 5.75 & 1.50 & 0.38 & 0.13 & 6.05 & 0.59 & 11.25 \\
\hline & SW3 & 0.10 & 5.57 & 0.55 & 1.62 & 0.09 & 2.98 & 0.28 & 4.22 \\
\hline \multirow[t]{5}{*}{ Jun } & DE1 & 2.02 & 2.28 & 0.10 & 0.12 & 0.66 & 2.37 & 0.04 & 16.56 \\
\hline & D0 & 1.28 & 19.52 & 1.33 & 6.96 & 0.38 & 19.42 & 0.63 & 6.85 \\
\hline & DW2 & 0.92 & 11.52 & 0.43 & 15.89 & 0.31 & 10.91 & 0.27 & 17.48 \\
\hline & SW1 & 0.54 & 7.90 & 0.59 & 10.32 & 0.12 & 6.81 & 0.32 & 13.54 \\
\hline & SW3 & 0.39 & 2.50 & 0.11 & 3.72 & 0.18 & 1.57 & 0.15 & 2.73 \\
\hline \multirow[t]{5}{*}{ Sep } & DE1 & 1.45 & 1.82 & 0.92 & 9.42 & 0.42 & 2.13 & 0.32 & 8.18 \\
\hline & D0 & 1.22 & 19.91 & 3.57 & 7.16 & 0.30 & 19.59 & 1.27 & 6.36 \\
\hline & DW2 & 0.50 & 11.97 & 2.47 & 16.89 & 0.18 & 10.92 & 0.73 & 15.42 \\
\hline & SW1 & 0.40 & 4.80 & 1.53 & 0.94 & 0.04 & 6.31 & 0.46 & 11.09 \\
\hline & SW3 & 0.01 & 2.32 & 0.27 & 1.90 & 0.09 & 0.49 & 0.11 & 2.71 \\
\hline \multirow[t]{5}{*}{ Dec } & DE1 & 0.85 & 2.27 & 2.19 & 9.97 & 0.25 & 2.46 & 0.67 & 9.03 \\
\hline & D0 & 0.85 & 20.08 & 7.59 & 6.74 & 0.27 & 20.05 & 2.58 & 6.65 \\
\hline & DW2 & 0.01 & 13.97 & 3.13 & 15.88 & 0.05 & 8.33 & 1.12 & 16.38 \\
\hline & SW1 & 0.27 & 5.47 & 1.61 & 0.19 & 0.10 & 4.84 & 0.42 & 11.33 \\
\hline & SW3 & 0.14 & 8.55 & 0.72 & 4.87 & 0.03 & 0.45 & 0.32 & 3.97 \\
\hline
\end{tabular}

Table 4. Annual average values of the amplitudes and phases of the prominent diurnal and semidiurnal tides, in thermospheric mass density, zonal wind and electron density.

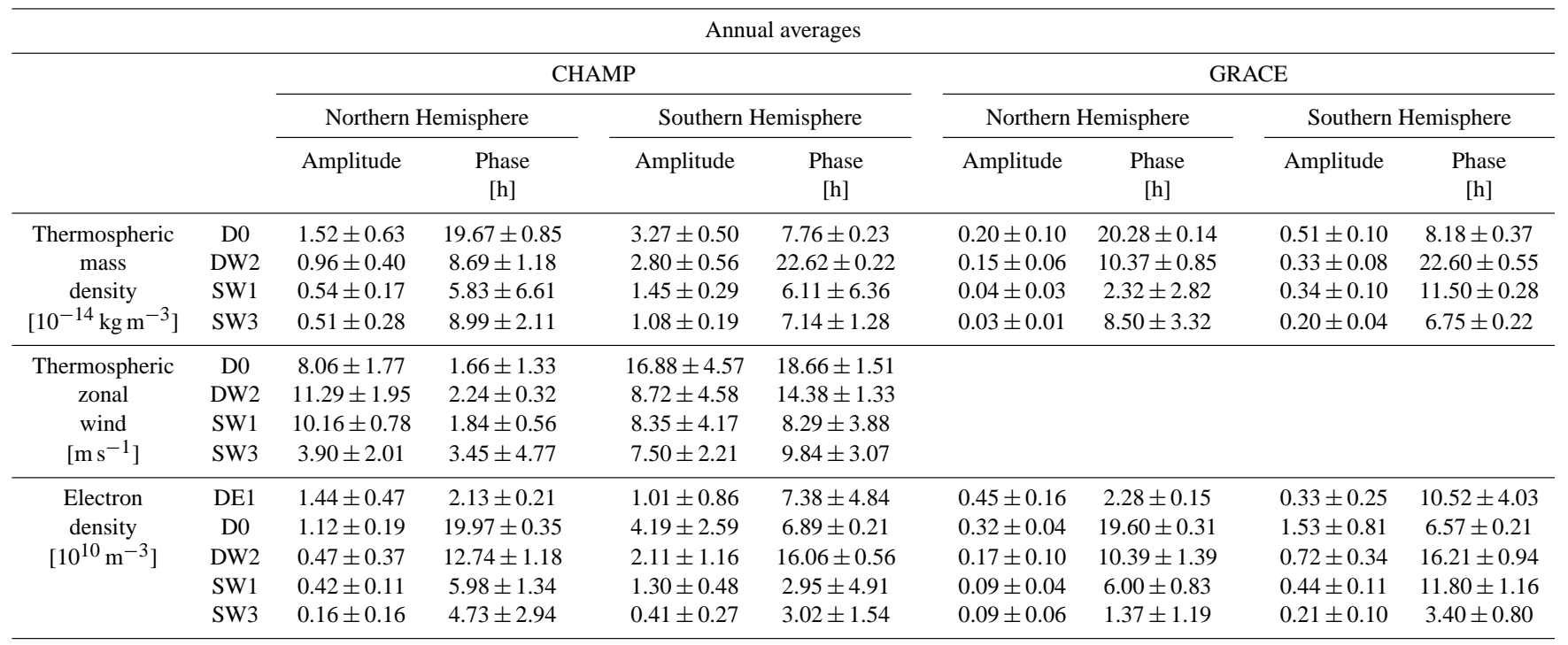


of migrating tides, DW1 and SW2, with the stationary planetary wave, SPW1. The tides D0, DW2, SW1, and SW3 vary in anti-phase in the two hemispheres. This is believed to be due to the tilt of the magnetic dipole field.

2. The thermospheric mass density is also dominated by wave-1 longitudinal features. Again, the diurnal tides D0 and DW2 are strongest. The wave-1 semidiurnal components, SW1 and SW3, are also present but significantly smaller. The phases of the diurnal tides exhibit an anti-phase relationship between the hemispheres. All phase values differ significantly from zonal wind phases, as expected.

3. We regard the thermospheric dynamics as the main driver for the electron density tidal structures. An example is the in-phase variation of D0 between electron density and mass density in both hemispheres. DW2 shows similarities in amplitude between the two densities, but large differences in phase. The prominent wave- 2 signature, DE1, in the Northern Hemisphere electron density is quite puzzling, present neither in the mass density nor in the zonal wind. Further studies are needed for fully understanding these relationships.

Acknowledgements. The CHAMP and GRACE missions were sponsored by the Space Agency of the German Aerospace Center (DLR) through funds of the Federal Ministry of Economics and Technology. The CHAMP and GRACE thermospheric mass density data are available at the website of air density models derived from multi-satellite drag observations (http://thermosphere.tudelft.nl/acceldrag/data.php). The work of Chao Xiong is supported by the Alexander von Humboldt foundation through a Research Fellowship for Postdoctoral Researchers. The work of Yun-Liang Zhou is supported by the National Nature Science Foundation of China (no. 41274194 and no. 40804049).

The service charges for this open-access publication have been covered by a Research Centre of the Helmholtz Association.

Topical Editor C. Jacobi thanks two anonymous referees for their help in evaluating this paper.

\section{References}

Bellchambers, W. H. and Piggott, W. R.: Ionospheric measurements made at Halley Bay, Nature, 182, 1596-1597, doi:10.1038/1821596a0, 1958.

Burns, A. G., Zeng, Z., Wang, W., Lei, J., Solomon, S. C., Richmond, A. D., Killen, T. L., and Kuo, Y.-H.: Behavior of the F2 peak ionosphere over the South Pacific at dusk during quiet summer condition from COSMIC data, J. Geophys. Res., 113, A12305, doi:10.1029/2008JA013308, 2008.
Chang, L. C., Lin, C.-H., Yue, J., Liu, J.-Y., and Lin, J.-T.: Stationary planetary wave and nonmigrating tidal signatures in ionospheric wave 3 and wave 4 variations in 2007-2011 FORMOSAT-3/COSMIC observations, J. Geophys. Res.-Space, 118, 6651-6665, doi:10.1002/jgra.50583, 2013.

Chapman, S. and Lindzen, R. S.: Atmospheric Tides: Thermal and Gravitational, D. Reidel Publishing Company, Dordrecht, Holland, 1970.

Chen, C. H., Lin, C. H., Chang, L. C., Huba, J. D., Lin, J. T., Saito, A., and Liu, J. Y.: Thermospheric tidal effects on the ionospheric midlatitude summer nighttime anomaly using SAMI3 and TIEGCM, J. Geophys. Res.-Space, 118, 3836-3845, doi:10.1002/jgra.50340, 2013.

Doornbos, E., Ijssel, J., Lühr, H., Förster, M., and Koppenwallner, G.: Neutral density and crosswind determination from arbitrarily oriented multiaxis accelerometers on satellites, J. Spacraft Rockets, 47, 580-589, doi:10.2514/1.48114, 2010.

Dudeney, J. R. and Piggott, W. R.: Antarctic ionospheric research, in: Upper Atmosphere Research in Antarctica, Antarct. Res. Ser., 29, edited by: Lanzerotti, L. J. and Park, C. G., 200-235, AGU, Washington, D. C., 1978.

England, S. L., Maus, S., Immel, T. L., and Mende, S. B.: Longitude variation of the E-region electric fields caused by atmospheric tides, Geophys. Res. Lett., 33, L21105, doi:10.1029/2006GL027465, 2006.

England, S. L., Immel, T. J., Huba, J. D., Hagan, M. E., Maute, A., and DeMajistre, R.: Modeling of multiple effects of atmospheric tides on the ionosphere: An examination of possible coupling mechanisms responsible for the longitudinal structure of the equatorial ionosphere, J. Geophys. Res., 115, A05308, doi:10.1029/2002JA009262, 2010.

Forbes, J. M.: Tidal and Planetary Waves, in: The upper Mesosphere and Lower Thermosphere: A Review of Experiment and Theory, Geophysical Monograph, 87, edited by: Johnson, R. M. and Killeen, T. L., AGU, 1995.

Forbes, J. M., Zhang, X., Ward, W., and Talaat, E.: Nonmigrating diurnal tides in the thermosphere, J. Geophys. Res., 108, 1033, doi:10.1029/2009JA014894, 2003.

Forbes, J. M., Russell, J., Miyahara, S., Zhang, X., Palo, S., Mlynczak, M., Mertens, C. J., and Hagan, M. E.: Tropospherethermosphre tidal coupling as measured by the SABER instrument on TIMED during July-September 2002, J. Geophys. Res., 111, A10S06, doi:10.1029/2005JA011492, 2006.

Hagan, M. E. and Forbes, J. M.: Migrating and nonmigrating diurnal tides in the middle and upper atmosphere excited by tropospheric latent heat release, J. Geophys. Res., 107, 4754, doi:10.1029/2001JD001236, 2002.

Hagan, M. E. and Forbes, J. M.: Migrating and nonmigrating semidiurnal tides in the upper atmosphere excited by tropospheric latent heat release, J. Geophys. Res., 108, 1062, doi:10.1029/2002JA009466, 2003.

Hagan, M. E. and Roble, R. G.: Modeling the diurnal tidal variability with the National Center for Atmospheric Research thermosphere-ionosphere-mesosphere-electrodynamics general circulation model, J. Geophys. Res., 106, 24869-24882, doi:10.1029/2001JA000057, 2001.

Hagan, M. E., Maute, A., and Roble, R. G.: Tropospheric tidal effects on the middle and upper atmosphere, J. Geophys. Res., 114, A01302, doi:10.1029/2008JA013637, 2009. 
Häusler, K. and Lühr, H.: Nonmigrating tidal signals in the upper thermospheric zonal wind at equatorial latitudes as observed by CHAMP, Ann. Geophys., 27, 2643-2652, doi:10.5194/angeo27-2643-2009, 2009.

He, M., Liu, L., Wan, W., Ning, B., Zhao, B., Wen, J., Yue, X., and Le, H.: A study of the Weddell Sea Anomaly observed by FORMOSAT-3/COSMIC, J. Geophys. Res., 114, A12309, doi:10.1029/2009JA014175, 2009.

Immel, T. J., Sagawa, E., England, S. L., Henderson, S. B., Hagan, M. E., Mende, S. B., Frey, H. U., Swenson, C. M., and Paxton, L. J.: Control of equatorial ionospheric morphology by atmospheric tides, Geophys. Res. Lett., 33, L15108, doi:10.1029/2006GL026161, 2006.

Jones Jr., M., Forbes, J. M., Hagan, M. E., and Maute, A.: Nonmigrating tides in the ionosphere-thermosphere: In situ versus tropospheric sources, J. Geophys. Res.-Space, 118, 2438-2451, doi:10.1002/jgra.50257, 2013.

Kil, H., Paxton, L. J., Lee, W. K., Ren, Z., Oh, S.-J., and Kwak, Y.-S.: Is DE2 the source of the ionospheric wavenumber 3 longitudinal structure?, J. Geophys. Res., 115, A11319, doi:10.1029/2010JA015979, 2010.

Lin, C. H., Liu, J. Y., Cheng, C. Z., Chen, C. H., Liu, C. H., Wang, W., Burns, A. G., and Lei, J.: Three-dimensional ionospheric electron density structure of the Weddell Sea Anomaly, J. Geophys. Res., 114, A02312, doi:10.1029/2008JA013455, 2009.

Lin, C. H., Liu, C. H., Liu, J. Y., Chen, C. H., Burns, A. G., and Wang, W.: Midlatitude summer nighttime anomaly of the ionospheric electron density observed by FORMOSAT-3/COSMIC, J. Geophys. Res., 115, A03308, doi:10.1029/2009JA014084, 2010.

Liu, H., Lühr, H., Watanabe, S., Köhler, W., Henize, V., and Visser, P.: Zonal winds in the equatorial upper thermosphere: Decomposing the solar flux, geomagnetic activity, and seasonal dependencies, J. Geophys. Res., 111, A07307, doi:10.1029/2005JA011415, 2006.

Liu, H., Yamamoto, M., and Lühr, H.: Wave-4 pattern of the equatorial mass density anomaly: A thermospheric signature of tropical deep convection, Geophys. Res. Lett., 36, L18104, doi:10.1029/2009GL039865, 2009.

Liu, H., Thampi, S. V., and Yamamoto, M.: Phase reversal of the diurnal cycle in the midlatitude ionosphere, J. Geophys. Res., 115, A01305, doi:10.1029/2009JA014689, 2010.

Lühr, H. and Manoj, C.: The complete spectrum of the equatorial electrojet related to solar tides: CHAMP observations, Ann. Geophys., 31, 1315-1331, doi:10.5194/angeo-31-1315-2013, 2013.

Lühr, H., Rother, M., Häusler, K., Alken, P., and Maus, S.: The influence of non-migrating tides on the longitudinal variation of the equatorial electrojet, Geophys. Res. Lett., 113, A08313, doi:10.1029/2008JA013064, 2008.

Lühr, H., Rother, M., Häusler, K., Fejer, B., and Alken, P.: Direct comparison of non-migrating tidal signatures in the electrojet, vertical plasma drift and equatorial ionization anomaly, J. Atmos. Sol.-Terr. Phy., 75-76, 31-43, doi:10.1016/j.jastp.2011.07.009, 2012.

McLandress, C. and Ward, W. E.: Tidal/gravity wave interactions and their influence on the large-scale dynamics of the middle atmosphere: Model results, J. Geophys. Res., 99, 8139-8155, doi:10.1029/94JD00486, 1994.
Oberheide, J., Hagan, M. E., Roble, R. G., and Offermann, D.: Sources of nonmigrating tides in the tropical middle atmosphere, J. Geophys. Res., 107, 4567, doi:10.1029/2002JD002220, 2002.

Oberheide, J., Forbes, J. M., Häusler, K., Wu, Q., and Bruinsma, S. L.: Tropospheric tides from 80 to $400 \mathrm{~km}$ : Propagation, interannual variability, and solar cycle effects, J. Geophys. Res., 114, D00I05, doi:10.1029/2009JD012388, 2009.

Oberheide, J., Forbes, J. M., Zhang, X., and Bruinsma, S. L.: Wave-driven variability in the ionosphere-thermospheremesosphere system from TIMED observations: What contributes to the "wave 4"?, J. Geophys. Res., 116, A01306, doi:10.1029/2010JA015911, 2011a.

Oberheide, J., Forbes, J. M., Zhang, X., and Bruinsma, S. L.: Climatology of upward propagating diurnal and semidiurnal tides in the thermosphere, J. Geophys. Res., 116, A01306, doi:10.1029/2011JA016784, 2011b.

Pancheva, D., Miyoshi, Y., Mukhtarov, P., Jin, H., Shinagawa, H., and Fujiwara, H.: Global response of the ionosphere to atmospheric tides forced from below: Comparison between COSMIC measurements and simulations by atmosphereionosphere coupled model GAIA, J. Geophys. Res., 117, A07319, doi:10.1029/2011JA017452, 2012.

Penndorf, R.: The average ionospheric conditions over the Antarctic, in Geomagnetism and Aeronomy, Antarct. Res. Ser., 4, 1-45, AGU, Washington, D.C., 1965.

Reigber, C., Lühr, H., and Schwintzer, P.: CHAMP mission status, Adv. Space Res., 30, 129-134, 2002.

Rishbeth, H.: The effect of winds on the ionospheric F2peak, J. Atmos. Terr. Phys., 29, 225-238, doi:10.1016/00219169(67)90192-4, 1967.

Rishbeth, H.: The effect of winds on the ionospheric F2peak-II, J. Atmos. Terr. Phys., 30, 63-71, doi:10.1016/00219169(68)90041-X, 1968.

Sagawa, E., Immel, T. J., Frey, H. U., and Mende, S. B.: Longitudinal structure of the equatorial anomaly in the nighttime ionosphere observed by IMAGE/FUV, J. Geophys. Res., 110, A11302, doi:10.1029/2004JA010848, 2005.

Tapley, B. D., Bettadpur, S., Watkins, M., and Reigber, C.: The gravity recovery and climate experiment: Mission overview and early results, Geophys. Res. Lett., 31, L09607, doi:10.1029/2004GL019920, 2004.

Thampi, S. V., Lin, C., Liu, H., and Yamamoto, M.: First tomographic observations of the midlatitude summer nighttime anomaly over Japan, J. Geophys. Res., 114, A10318, doi:10.1029/2009JA014439, 2009.

Wan, W., Xiong, J., Ren, Z., Liu, L., Zhang, M.-L., Ding, F., Ning, B., Zhao, B., and Yue, X.: Correlation between the ionospheric WN4 signature and the upper atmospheric DE3 tide, J. Geophys. Res., 115, A11303, doi:10.1029/2010JA015527, 2010.

Wu, Q., Ortland, D. A., Foster, B., and Roble, R. G.: Simulation of nonmigrating tide influences on the thermosphere and ionosphere with a TIMED data driven TIEGCM, J. Atmos. Sol.-Terr. Phy., 90-91, 61-67, doi:10.1016/j.jastp.2012.02.009, 2012.

Xiong, C. and Lühr, H.: Nonmigrating tidal signatures in the magnitude and the inter-hemispheric asymmetry of the equatorial ionization anomaly, Ann. Geophys., 31, 1115-1130, doi:10.5194/angeo-31-1115-2013, 2013.

Xiong, C. and Lühr, H.: The Midlatitude Summer Night Anomaly as observed by CHAMP and GRACE: Interpreted 
as tidal features, J. Geophys. Res.-Space, 119, 4905-4915, doi:10.1002/2014JA019959, 2014.

Xiong, C., Lühr, H., and Stolle, C.: Seasonal and latitudinal variations of the electron density nonmigrating tidal spectrum in the topside ionospheric F-region as resolved from CHAMP observations, J. Geophys. Res.-Space, online first, doi:10.1002/2014JA020354, 2014a.
Xiong, C., Lühr, H., Ma, S. Y., and Schlegel, K.: validation of GRACE electron densities by incoherent scatter radar data and estimation of plasma scale height in the topside ionosphere, J. Adv. Space Res., online first, doi:10.1016/j.asr.2014.07.022, 2014b. 